University of Nebraska - Lincoln

DigitalCommons@University of Nebraska - Lincoln

\title{
Teacher Factors Associated with Preschool Teacher-Child Relationships: Teaching Efficacy and Parent-Teacher Relationships
}

\author{
Li-Chuan Chung \\ National Hualien Teachers College, Taiwan, ROC \\ Christine Marvin \\ University of Nebraska - Lincoln, cmarvin1@unl.edu \\ Susan Churchill \\ University of Nebraska - Lincoln, schurchill2@unl.edu
}

Follow this and additional works at: https://digitalcommons.unl.edu/specedfacpub

\footnotetext{
Chung, Li-Chuan; Marvin, Christine; and Churchill, Susan, "Teacher Factors Associated with Preschool Teacher-Child Relationships: Teaching Efficacy and Parent-Teacher Relationships" (2005). Special Education and Communication Disorders Faculty Publications. 86.

https://digitalcommons.unl.edu/specedfacpub/86
}

This Article is brought to you for free and open access by the Department of Special Education and Communication Disorders at DigitalCommons@University of Nebraska - Lincoln. It has been accepted for inclusion in Special Education and Communication Disorders Faculty Publications by an authorized administrator of DigitalCommons@University of Nebraska - Lincoln. 


\title{
Teacher Factors Associated with Preschool Teacher-Child Relationships: Teaching Efficacy and Parent-Teacher Relationships
}

\author{
Li-Chuan Chung, ${ }^{1}$ Christine A. Marvin, ${ }^{2}$ and Susan L. Churchill ${ }^{2}$ \\ 1. National Hualien Teachers College, Taiwan, ROC \\ 2. University of Nebraska-Lincoln, 202 Barkley Memorial Center, Lincoln, NE 68583-0732, USA \\ Corresponding author - C. A. Marvin, tel 402 472-5483, email cmarvin1@unl.edu
}

\begin{abstract}
The present study investigated specific teacher factors that potentially influence teacher-child relationships with preschool-age children. One demographic questionnaire and three rating scales were used to survey 152 head teachers of 3-6-year-old children in community-based childcare and preschool centers in one midwestern state. There were 46 teachers who reported on their relationship with a child with a disability or concerning developmental delay. Positive correlations were found between teacher-child relationships and the teachers' educational backgrounds, self-reported teaching efficacy, and parent-teacher relationships. The parent-teacher relationship appeared to be the strongest teacher-related factor predicting the quality of teacher-child relationships. Compared to other teachers, the teachers of children with delays or disabilities reported comparable parent-teacher relationships and more positive teacher-child relationships, especially when more than one child with concerns was reportedly enrolled in the classroom. Teachers with children who had developmental delays reported lower teaching efficacy scores. The role of parent-teacher relationships is highlighted as a possible moderator when teachers feel less than capable or positive about individual children in their program.
\end{abstract}

Keywords: teacher-child relationships, parent-teacher relationships, teacher efficacy, preschool children, disabilities

Due to the increasing rates of maternal employment and single parenthood (National Center for Education Statistics, 1998), more and more children spend time with teachers in school-like settings before they enter elementary school. Teachers, like parents, are considered important and capable social partners in scaffolding young children's learning and social interactions (Berk \& Winsler, 1995; Howes, 2000). In addition, the teacher-child relationship is considered a stable predictor for young children's early school adjustment and future peer relationships (Birch \& Ladd, 1997; Howes, Matheson, \& Hamilton, 1994; Pianta, Nimetz, \& Ben- nett, 1997). Furthermore, a positive teacher-child relationship during the preschool years can act as a protective factor and reduce the chances of children's referral to special education, retention in kindergarten classrooms (Pianta, Steinberg, \& Rollins, 1995), and social withdrawal or aggression in second grade (Howes, 2000). Changes in the teacher-child relationship are associated with changes in children's social competence with peers (Howes \& Hamilton, 1992). Although much has been written about the correlation between teacher-child relationships and children's learning outcomes (Birch \& Ladd, 1997; Pianta et al., 1997), 
not all studies point to positive relationships and positive outcomes (Egeland, Kalkoske, Gottesman, \& Erickson. 1990; Howes \& Ritchie, 1998). The factors influencing the quality of teacher-child relationships have not been fully explicated in the research literature despite their importance. There is evidence to show that the quality of relationships between teachers and children can be influenced by at least three potential sets of factors. These include the teaching environment, the child, and the teacher. This study looks specifically at teacher factors and a potentially challenging child factor, namely disability or developmental delay. Teacher expectations for children and lack of teaching confidence when dealing with these children may result in poorer teacher-child relationships. Moderators of this potentially negative relationship must be explored. The teacher's relationship with a parent may be one factor that can overcome any of the teacher's negative feelings and approaches.

\section{Influential factors}

\subsection{Environment}

The environment can positively or negatively impact the teacher's interactions and ultimate relationship with the child. For instance, when a classroom is too crowded, teachers may spend much of their time dealing with disruptions and managing children's behaviors (Greenman, 1988). When the number of children increases per teacher present, teachers tend to use more directive and prohibitive speech toward children (Schaffer \& Liddell, 1984) and consequently, the interactions between these teachers and children are often less than positive (Nordquist \& Twardosz, 1990; Olds, 1982). Furthermore, other studies have noted that when available materials in the classroom or center are not specifically selected to match the children's preferences, interests, and abilities, and classroom routines are inconsistent and unpredictable, the children are less likely to make safe and useful choices and transitions or engage in appropriate activities and behaviors (Hohmann \& Weikart, 1995; McGee, Daly, Izeman, Mann, \& Risley, 1991), Teacher-child interactions in these contexts are not likely to be positive. Some teachers, however, have been observed having positive interactions with children regardless of the challenging environmental conditions. For example, Mill and Romano-White (1999) reported that teachers with a large number of children in their care $(M=17)$ were more affectionate with the children than teachers with a small number of children in the classrooms $(M=13)$. Classroom arrangements, therefore, do not always predict the same interactive behaviors between teachers and children (Howes. 1997). Environmental factors may explain some but not all teacher-child relationships.

\subsection{Children}

In addition to environmental factors, many studies have shown that children's characteristics can also influence teachers' relationships with them in different ways. For example, children with behavioral problems, and boys in particular, are more likely to provoke negative responses and conflicts from their teachers than compliant children or girls (Arnold, McWilliams, \& Arnold, 1998; Fagan, 1990; Pianta et al. 1997). Some teachers are more likely to interact negatively with boys even when the child has not made a negative approach to the teacher (Quay \& Jarrett, 1986). Furthermore, children with disabilities have also prompted negative attitudes from teachers. Some teachers have been observed providing unneeded assistance and more directive interactions or ignoring the help requests from children with disabilities more often than those of typically-developing children (Stipek \& Sanborn, 1985). Keogh and Burstein (1988) also reported that teachers interacted more negatively with children with disabilities than children without disabilities, even when children without disabilities had similar difficult temperaments.

Other researchers, however, would suggest that child characteristics are not responsible for negative teacher-child relationships. For example, Paget, Nagle, and Martin (1984) found that children with easy temperaments received less praise from their teachers than the children with difficult temperaments, and Howes and Ritchie (1998) reported that children with serious emotional and behavioral problems do not always prompt negative interactions with all teachers. Bullock (1993) and Van der Werfhost (1986) have also suggested that praise from teachers is not always related to children's easy/difficult temperaments. Furthermore, research on the quality of parent-child relationships suggests that children establish similar relationships with new teachers. Howes and Hamilton (1992) and Nimetz (1992) each report that when children have positive parent-child relationships they are more likely to establish positive teacher-child relationships. Similarly, if children have negative parentchild relationships at home, they are more likely to establish negative teacher-child relationships when they enter formal care or education settings. Some teachers, however, are able to establish positive relationships with children despite the presence of a negative parent-child relationship (Sroufe, 1983). Reasons for this shift are unclear, but may be related to teacher factors as yet unexplored. These findings suggest that quality 
of teacher-child relationships is a complex combination of factors.

\subsection{Teachers}

Factors associated with the teacher's history and personal qualities and his/her ability to effect change with children may also contribute to the quality of the teacher-child relationship in any setting (Howes \& Ritchie, 1998; Roberts, Bailey, \& Nychka, 1991). This study chose to examine teachers' education and experience, teaching efficacy, and teacher-parent relationships. The first factors, teacher education and experience have been reported previously as influential in the quality of teacher-child relationships (Kontos \& Wilcox-Herzog, 2001). Studies indicate that teachers with limited education and coursework about child development and early childhood education are more likely to be insensitive and harsh to children in their care (Kontos \& Wilcox-Herzog, 2001). It is generally believed that teachers with more professional education are more likely to use positive interactions with children and are less likely to use punitive approaches (Arnett, 1989; Howes, 1997; White, 1993). The National Child Care Staffing Study reported no relationship between years of experience teaching young children and teachers' sensitivity to care-giving needs or the quality of the learning environment (Howes, Whitebook, \& Phillips. 1992; Whitebook, Howes, \& Philips. 1998). Howes (1997) and Howes and Ritchie (1998), however, suggested that teachers who were committed to their role (longer work experience) or who had increased knowledge of child development (more education) were associated with an increase in secure teacher-child relationships.

The second factor - teaching efficacy - has received attention in studies of elementary school teachers but not nearly as much with early childhood populations. How teachers perceive their roles and teaching abilities and the expectations they hold for the children may influence their interactions with children (White, 1993). Teaching efficacy, or the teacher's belief that her or his actions/skills can manage expected situations and learning with children (Bandura, 1995), has been identified as an important variable in noting differences in teaching effectiveness (Gibson \& Dembo, 1984; Woolfolk, Rosoff, \& Hoy, 1990). The attitudes and beliefs of early childhood teachers, however, have pointed to their feelings of limited competence with children demonstrating challenging behaviors and limited influence in changing those behaviors (Boulton, 1997; File, 1994). There is some evidence, however, that some teachers of preschool-age children can change their negative relationships with children who display problematic behavior (Howes \& Ritchie, 1998; Nordquist \& Twardosz, 1990).

The last factor, parent-teacher relationships, has not been examined in its relationship to teacher-child relationships directly. Bronfenbrenner's ecological theory would suggest, however, that a meso-system of teacher and parent interactions could support or disrupt the micro-systems of parent-child and teacherchild interactions and subsequent child development outcomes (Bronfenbrenner, 1979). In addition, research on parent-professional relationships and parent support programs suggest direct and indirect influences on child outcomes (Cmic, Greenberg, \& Slough, 1986; Dunst, Trivette, \& Deal, 1988; Emery, 1982; Nimetz, 1992). These child outcomes, as well as changes in the parent-child relationships, could directly or indirectly impact the teacher-child relationship (Howes \& Hamilton, 1992). Furthermore, research on parent involvement suggests that the family-school (parent-teacher) relationship can influence the child's development and school experiences (Bronson, Peirson, \& Tivnan, 1984; Christenson, 2000; Pianta \& Walsh, 1996).

Not all early childhood teachers, however, have positive comments to make about parents. Teachers seem to like parents who view the teachers and their programs as important supports in their lives, but teachers do sometimes express negative attitudes about parents' child-rearing practices (Kontos, 1987; Kontos, Raikes, \& Woods, 1983). Furthermore, parents and teachers are sometimes unaware of each others' expectations and differ in their opinions about proper child-rearing practices at home (Bernhard, Lefebvre, Kilbride, Chud, \& Lange, 1998). These negative parent-teacher relationships could influence learning outcomes for the children. The literature on parentteacher communication with young children with disabilities, however, would suggest that positive parent-teacher relationships among early interventionists are not only possible but common (Romer \& Umbriet, 1998). For these reasons, the examination of parentteacher relationships as a teacher factor in teacherchild relationships appears warranted.

As the previous review demonstrates, the specific influences on the teacher-child relationship are unclear. The importance of this relationship for positive child outcomes, however, makes it imperative that we continue to explore possible influences. This study examines the association that exists for various teacher factors and the quality of teacher-child relationships, particularly teaching efficacy and the quality of parent-teacher relationships. No positive relationship across these factors would suggest that influences from environmental or child factors were responsible in establishing quality teacher-child relationships. 


\section{Method}

\subsection{Participants}

All directors of preschool or childcare centers in Nebraska accredited by the National Association for the Education of Young Children (NAEYC) $(n=38)$ as well as $20 \%$ (randomly selected) of the state licensed childcare or preschool programs in the state $(n=62)$ were invited to participate. A total of 67 directors agreed to distribute survey packets to all their head teachers. These centers included 20 programs accredited and 47 state-licensed but not accredited childcare or preschool programs. Two-hundred seventy-one head teachers of 3-6-year-old children were subsequently invited by their directors to participate in this study. Each teacher was asked to complete one Teacher Information Survey, and one Teacher Beliefs Scale (TBS). Given the varying enrollments and a desire for random selection of children, teachers were asked to select the top four children from their alphabetized class rosters and complete a Student-Teacher Relationships Scale (STRS), and Parent-Teacher Relationship Scale (PTRS) for each child. The two completed forms and eight completed scales were returned in a self-addressed stamped envelope.

A total of 152 (58\%) teachers returned completed surveys reflecting relationships with 608 children (four per teacher), These surveys represented 81 (53\%) teachers from NAEYC-accredited childcare or preschool programs and $71(47 \%)$ teachers from state-licensed but unaccredited programs. Table 1 presents the teachers' demographic information. The participants were primarily female $(97 \%)$, and Caucasian (82\%), ranging in age from 18 to 60 years (63\% were between 21 and 40 ). Nearly half of these teachers $(46 \%)$ had at least a bachelor's degree; $20 \%$ of these teachers majored in child development, early childhood education, or a related field. Another $29 \%$ of the participants in this study had at least an associate degree or certificate program completed with emphasis in child development or early childhood education. Twenty-five percent of the participants had completed only a high school education. Nearly two-thirds of the teachers (63\%) had less than 10 years of teaching experience with young children while $31 \%$ had more than 10 years experience; $6 \%$ had less than 1 year of work experience with young children.

A subset of 46 teachers reported 63 children to have a known disability or were being considered for referral to special education programs for concerns regarding developmental delays, noncompliant behavior, or challenging speech-language patterns. This subset of data was used to explore the possible relationship between disability (child factor) and teaching efficacy (Howes \& Ritchie, 1998) and teacher-child relationship in preschool populations.
Table 1. Demographic information of teacher participants

\begin{tabular}{|c|c|c|}
\hline & $N(152)$ & Percent \\
\hline \multicolumn{3}{|l|}{ Ethnicity } \\
\hline Caucasian & 125 & 82 \\
\hline African American & 21 & 14 \\
\hline Others & 6 & 4 \\
\hline \multicolumn{3}{|l|}{ Gender } \\
\hline Female & 148 & 97 \\
\hline Male & 4 & 3 \\
\hline \multicolumn{3}{|l|}{ Age } \\
\hline 20 or younger & 6 & 4 \\
\hline $21-30$ & 55 & 36 \\
\hline $31-40$ & 41 & 27 \\
\hline $41-50$ & 31 & 20 \\
\hline 51 or older & 19 & 13 \\
\hline \multicolumn{3}{|l|}{ Education levels } \\
\hline High school or less & 38 & 25 \\
\hline College courses & 44 & 29 \\
\hline Bachelor's degree & 66 & 43 \\
\hline MA/MS or higher & 4 & 3 \\
\hline \multicolumn{3}{|l|}{ Coursework in CD or ECE } \\
\hline One course or less & 11 & 7 \\
\hline Many courses & 68 & 45 \\
\hline Major for AA degree/Certificate & 42 & 28 \\
\hline Major for BS degree or higher & 31 & 20 \\
\hline \multicolumn{3}{|l|}{ Teaching experience } \\
\hline Less than a year & 9 & 6 \\
\hline $1-10$ years & 95 & 63 \\
\hline 11-20 years & 43 & 28 \\
\hline More than 20 years & 5 & 3 \\
\hline \multicolumn{3}{|l|}{ Programs } \\
\hline NAEYC accredited & 81 & 53 \\
\hline Non-accredited & 71 & 47 \\
\hline
\end{tabular}

$\mathrm{CD}=$ child development; $\mathrm{ECE}=$ early childhood education

\subsection{Instruments}

\subsubsection{Teacher Information Survey}

This one-page, 10-item questionnaire was developed to collect necessary demographic information from the participating teachers. The information included the teachers' (a) gender and age, (b) highest educational level and major, (c) years of teaching experience with young children, and (d) their level of professional training in child development or early childhood education.

\subsubsection{Student-Teacher Relationship Scale (STRS)}

The STRS is a 28-item standardized questionnaire which assesses teachers' perceptions of their relation- 
ship with individual children (Pianta, 1992). The wording of the STRS was adapted slightly for purposes of this study in order to reflect the younger children and teachers in both preschool and child care settings used in this study. Each teacher completed the STRS for four randomly selected children in their classroom. For the purpose of this study, only total STRS scores were used; the mean total scores for four children were used for data analyses. Mean scores $>1$ SD above the mean for the sample were considered reflective of more positive teacher-child relationships; mean scores $<1$ SD below the mean for the sample were considered reflective of less positive teacher-child relationships (Pianta, 1996).

In addition, at the top of each STRS, teachers were asked to indicate the child's initials, gender, and whether the child had an identified disability; if no current disability was noted, teachers were asked to indicate if and why they may be considering a referral to special education programs for this child.

\subsection{Parent-Teacher Relationship Scale (PTRS)}

The PTRS is an adaptation of the Parent-Caregiver Relationship Scale by Elicker, Noppe, and Noppe (1997). This scale asked teachers to rate 29 items $(1=$ strongly disagree, $5=$ strongly agree) related to their relationship with the parents of individual children ages 3-6 years who were currently enrolled in their childcare or preschool settings (Chung, 2000). The items explored dimensions of trust/confidence and collaboration between the teachers and the parents of the four children for whom the teachers completed a STRS. Only the mean scores from the teacher's four completed scales were used for data analyses.

\subsubsection{Teacher Beliefs Scale (TBS)}

The TBS is a 32-item adaptation of the Teacher Efficacy Scale by Soodak and Podell (1996) and is designed to examine early childhood teachers' perceptions of their own teaching efficacy (Chung, 2000). Teachers were asked to rate each statement on the TBS for its applicability to their beliefs about teaching on a four-point scale $(1=$ strongly disagree, $4=$ strongly agree). Mean scores on the TBS were used for data analyses.

\subsection{Data analyses}

The mean STRS scores were used to compare teachers with different levels of education training, years of teaching experience with preschool children, and high (above the mean) and low (below the mean) teaching efficacy (TBS scores) and more positive and more negative parent-teacher relationships (PTRS scores). Pearson correlations and multiple regression analyses were used to establish the relationship between these teacher factors and the predictive value of individual factors on the teacher-child relationship (STRS scores).

\section{Results}

\subsection{Positive relationships and beliefs}

Group means were established for each of the scales. Table 2 reports the means, standard deviations, and sample size for each scale. Although some researchers (Pianta, 1996; Pianta \& Nimetz, 1991) might suggest the lower STRS scores reflect "negative" relationships, the small sample in the present study discouraged the use of strict interpretation; therefore, they are referred to in this study as simply lower STRS scores.

A review of the results in Table 2 demonstrates that similar numbers of teachers report higher and lower scores on the student-teacher relationship, parentteacher relationship, and teaching efficacy scales. The sample appears to be normally distributed with an adequate range on all the variables. Preschool teachers do exhibit variability in their relationships with children,

Table 2. STRS a mean scores and standard deviations (SD) for teacher factors

\begin{tabular}{|c|c|c|c|}
\hline & $N$ & Percent & $\begin{array}{r}\text { Mean STRS } \\
\text { score }(S D)\end{array}$ \\
\hline Total group & 152 & 100 & $100.84(6.9)$ \\
\hline \multicolumn{4}{|l|}{ Degrees } \\
\hline High school & 38 & 25 & $97.90(7.4)$ \\
\hline Associate & 44 & 29 & $100.60(6.9)$ \\
\hline Bachelor's or higher & 70 & 46 & $102.60(6.2)$ \\
\hline \multicolumn{4}{|l|}{ Coursework in $\mathrm{CD} / \mathrm{ECE}^{\mathrm{b}}$} \\
\hline One course or less & 11 & 7 & $96.05(7.1)$ \\
\hline Many courses & 68 & 45 & $99.98(7.0)$ \\
\hline AA degrees/certificate & 42 & 28 & $101.61(6.7)$ \\
\hline BS degrees or higher & 31 & 20 & $103.37(6.1)$ \\
\hline \multicolumn{4}{|c|}{ Parent-teacher relationships $\left(\right.$ mean $P T R S^{\mathrm{c}}$ score $\left.=115\right)$} \\
\hline PTRS scores $>$ mean & 75 & 49 & $103.27(5.6)$ \\
\hline PTRS scores $<$ mean & 77 & 51 & $98.46(7.3)$ \\
\hline > 1 SD (130) & 22 & 14 & \\
\hline$<1$ SD $(100)$ & 21 & 14 & \\
\hline \multicolumn{4}{|c|}{ Teaching efficacy $\left(\right.$ mean $T B S^{\mathrm{d}}$ score $\left.=92\right)$} \\
\hline$T B S$ scores $>$ mean & 81 & 53 & $102.59(6.2)$ \\
\hline$T B S$ scores $<$ mean & 71 & 47 & $99.89(7.2)$ \\
\hline$>1 \mathrm{SD}(110)$ & 29 & 19 & \\
\hline$<1 \mathrm{SD}(90)$ & 20 & 13 & \\
\hline
\end{tabular}

a. Student-Teacher Relationship Scale

b. CD: child development; ECE: early childhood education

c. Parent-Teacher Relationship Scale

d. Teacher Beliefs Scale 
Table 3. ANOVA for significant mean differences on the STRS ${ }^{\text {a }}$ among teachers with different amounts of coursework in child development or early childhood education and teachers with various education degrees $(N=152)$

\begin{tabular}{lrrrl}
\hline Source of variation & \multicolumn{1}{c}{$S S$} & $d f$ & $M S$ & \multicolumn{1}{c}{$F$} \\
\hline Education degrees & & & & \\
Between groups & 543.22 & 2 & 271.61 & 5.99 \\
Within groups & 6753.06 & 149 & 45.32 & $p=.003$ \\
Total & 7296.28 & 151 & & \\
Coursework in CD/ECE & & & \\
Between groups & 527.08 & 3 & 175.69 & 3.84 \\
Within groups & 6769.20 & 148 & 45.74 & $p=.001$ \\
Total & 7296.28 & 151 & & \\
\hline
\end{tabular}

a. Student-Teacher Relationship Scale.

b. $\mathrm{CD}=$ child development; $\mathrm{ECE}=$ early childhood education

parents, and in their teaching efficacy. The mean STRS scores were examined for teachers who were above and below the mean on each of the various teacher factors to determine relationships between these factors and the student-teacher relationship. These findings are addressed individually.

\subsection{Educational training and relationships}

Results suggest that the teachers with the highest STRS scores generally held BS degrees or higher, with college majors in child development and/or early childhood education. These data support the findings described by Kontos and Wilcox-Herzog (2001): that the mean scores on the STRS were statistically higher for teachers with greater amounts of coursework in child development or early childhood education $(F(3,148)$ $=3.84, p=.011)$ and for teachers with higher-level education degrees $(F(2,149)=5.93, p=.003$ ) (see Table $3)$. Weak (but positive) correlations were evident for the reported teacher-child relationships (STRS scores) with (a) teachers' education degrees $(r=.27, p=.000)$ and (b) amount of completed coursework in child development or early childhood education $(r=.26, p=$ .001). Similar findings were reported by Howes (1997) and support the view that a teacher's college major might provide additional information for better understanding teachers' educational backgrounds and their subsequent teacher-child relationships over and above the knowledge of a degree.

\subsection{Teaching experience and relationships}

Unlike some previous studies, no significant correlation was found in the present study between teachers' years of teaching experience and their teacher-child relationships $(r=.06, p=.48)$. Nor was there a signif- icant difference noted in the mean scores on the STRS among teachers with less than 1 year, 1-10 years, 11-20 years, and more than 20 years of teaching experience $(F(3,148)=1.17, p=.32)$. These findings suggest that the teachers with more experience with children under 6 years of age did not appear to be different in their relationships with young children than teachers with less experience. The categories used to analyze years of teaching experience were broad and may have disguised some relationships.

\subsection{Teacher beliefs, parents and teacher-child relationships}

Pearson product-moment correlations were calculated for each teacher factor studied and the teachers' STRS mean scores. A weak but positive and significant correlation was noted between teaching efficacy and teacher-child relationships as reported on the TBS and STRS $(r=.25, p=.006)$ (see Table 4$)$. The teachers with higher teaching efficacy scores had higher teacherchild relationships scores on the STRS. Twenty-four teachers $(16 \%)$ had TBS scores one standard deviation above the mean for the group. A total of 15 of these teachers with stronger teaching efficacy had STRS scores above the group mean and 18 had PTRS scores above the mean for the total sample. A significant. positive correlation was found to exist between parentteacher and teacher-child relationships $(r=.41, p=$ $.000)$. Again, the teachers with more positive parentteacher relationships had more positive teacher-child relationships in the present sample.

\subsection{Predictive teacher factors}

In order to understand more thoroughly the relationship between the teacher factors studied and teacherchild relationships, as well as to determine which teacher factor(s) might have the most influence on teacher-child relationships, a multiple regression analysis was utilized to evaluate the overall multiple correlation-squared $\left(R^{2}\right)$ and beta value $(\beta)$ for each teacher factor. The independent variables were entered randomly into the multiple regression equation since previous research has not established one factor as more predictive than others. Teachers' coursework in child development/early childhood education, education degrees, years of teaching experience, teaching efficacy, and parent-teacher relationships were therefore considered all at once. Table 5 presents the summary of the results for the multiple regression analysis.

Collectively, all the teacher factors accounted for approximately $24 \%$ of the variance in teacher-child relationships. Results of the multiple regression analyses 
Table 4. Inter-correlations for independent (teacher factors) and dependent variables $\left(S T R S^{\mathrm{a}}\right)(N=152)$

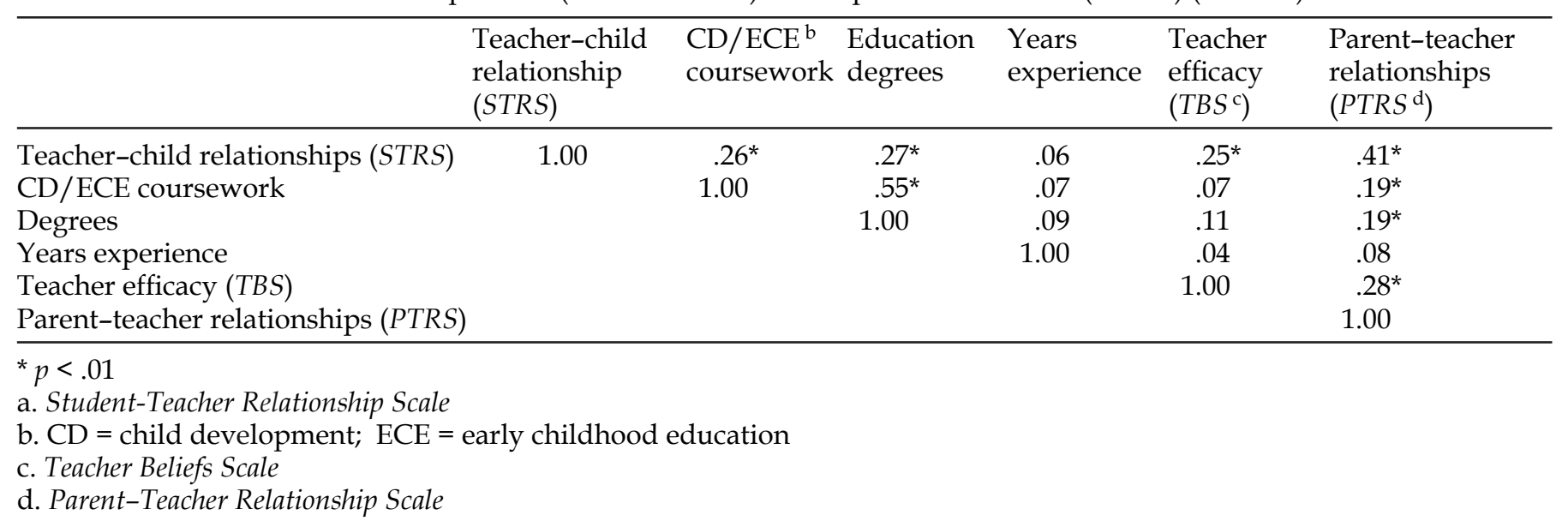

suggest only one teacher factor appears with a significantly different beta value: parent-teacher relationships $(t=4.26, p=.000, \beta=.39)$.

Data for 29 teachers $(19 \%)$ who reported the highest mean scores on the STRS (> 1 SD), suggesting the most positive teacher-child relationships in the present study, were examined separately; All 29 of these teachers had completed courses in child development or early childhood education and more than half majored in this field. Fourteen of these teachers had bachelors' degrees, 11 had associate degrees, and 4 had only high school diplomas. The teachers were split in how long they had worked with young children with 17 reporting $<10$ years of experience and 12 reporting 11-20+ years of experience. More than half these teachers (19) were employed in accredited programs. Also the TBS and PTRS scores were above the group mean for more than half these teachers,

In contrast, 20 teachers (13\%) with the lowest STRS scores $(<1 S D)$ presented a very different profile. Although the majority had completed courses in child development or early childhood education, only 6 had majored in this field in their college degree programs. Half of these teachers (10) had only a high school di- ploma. Again, however, the experience of these teachers was split between 12 who had less (<10 years) and 8 who had more (11-20+ years). Accredited programs were represented by only 5 of these teachers and TBS and PTRS scores were below the mean for 15 and 17 of these teachers, respectively.

In order to explore further the relationship between teaching efficacy and STRS scores, a subset of data was analyzed for the 46 teachers who reported 63 children having known disabilities or concerning behaviors. The mean STRS score for these teacher-child relationships was 107.5; above the mean of 100.8 for the entire group (range: 79-132). The teachers reporting only one randomly selected child with developmental concerns $(n=32)$, however, had the lowest mean STRS scores (98.9), while teachers who randomly selected two, three, or four children with such delays/ disabilities generally had higher STRS scores; the mean for these teachers was 107.5-114, far above the group mean of 100.84 . In contrast, the reported parentteacher relationships for all 63 children were similar to the larger group mean of 115 with a PTRS mean score of 114 (range: 72-150). Finally the mean TBS score of 87.8 for these 46 teachers was below the group mean of

Table 5. Results of multiple regression analysis $(N=152)$ dependent variable: $S T R S^{\text {a }}$ scores

\begin{tabular}{|c|c|c|c|c|c|}
\hline All independent variables & Final beta & $\begin{array}{c}\text { Total } R^{2} \\
.24\end{array}$ & $\begin{array}{c}d f 1 \\
5\end{array}$ & $\begin{array}{l}d f 2 \\
146\end{array}$ & $t$-value \\
\hline $\begin{array}{l}\text { Teaching efficacy }\left(T B S^{b}\right) \\
\text { Parent-teacher Relationship }\left(P T R S^{\mathrm{c}}\right) \\
\text { Years experience } \\
\text { Education degrees } \\
\text { CD/ECE }{ }^{\mathrm{d}} \text { coursework }\end{array}$ & $\begin{array}{l}.14 \\
.39 \\
.01 \\
.13 \\
.12\end{array}$ & & & & $\begin{array}{l}1.85 \\
4.26^{*} \\
.09 \\
1.48 \\
1.34\end{array}$ \\
\hline
\end{tabular}

$* p<.05$

a. Student-Teacher Relationship Scale

b. Teacher Beliefs Scale

c. Parent-Teacher Relationship Scale

d. $C D=$ child development; ECE = early childhood education 
92 (range 73-111) and suggests a poor teaching efficacy for the teachers of children with developmental/educational challenges. The number of reported children with delays/disabilities per teacher did not affect this finding of poorer teaching efficacy.

\section{Discussions and implications}

Teacher factors were responsible collectively for $24 \%$ of the variance in the teacher-child relationships in the present study. Although the majority of variance is explained by other unexamined factors, the present study reinforced the importance of the teachers' training/education in the quality of teacher-child relationships and identified new factors that might be amenable to change and/or education. In particular, the quality of the parent-teacher relationship would appear to influence the quality of the teacher-child relationship. Attention to these factors for new teachers and teacher preparation programs could possibly influence the relationships teachers establish with young preschool-age children and their parents and thereby the overall outlook for the children's future school success.

\subsection{Educational preparation}

There is no doubt about the important relationship between teachers' educational backgrounds and their relationships with young children. The results of the present study replicate the patterns established in previous research and support the national calls for higher education/training requirements for early childhood professionals (McGaha, Snow, \& Teleki, 2001). Teachers with a bachelors' or AA degree and a major in child development or early childhood education would be preferable, given the ability of these teachers to establish positive teacher-child relationships in the present study. Current licensing regulations for daycare programs in many states, however, only require such educational standards for program directors. All teachers should be encouraged to pursue a similar level of training if positive teacher-child relationships are the goals of these programs.

\subsection{Teaching experience}

Similar to the National Child Care Staffing Study (Howes et al., 1992), the present study found no relationship between years of experience teaching young children and teachers' sensitivity to care-giving needs or the quality of the learning environment. Like the teachers described by Oakes and Caroso (1990) and White (1993), these preschool teachers reported both positive and negative relationships regardless of how long they had been teaching young children. A limita- tion to this factor in the present study was its measurement. The large number of teachers with 1-10 years of experience in a single category may have camouflaged the influence of experience for statistical analyses. If groups of participants were clustered in smaller ranges, such as 1-5 and 5-10 years, teaching experience may have been a more influential factor in this study. However, as Kontos and Wilcox-Herzog (2001) suggest, most teachers' work experience with young children may not be consistently linked to their in-class teaching behaviors or the overall classroom quality. We would suggest that work experience would have a greater impact when that experience occurs under the guidance of a capable mentor or when preceded by relevant training, such as a practicum under the close supervision of an experienced teacher.

\subsection{Teaching Efficacy}

Although not causal in nature, teaching efficacy can be considered an important trait for influencing both parent-teacher and teacher-child relationships. Teaching efficacy played a small but positive role in explaining the teacher-child relationships in the present study. The teachers with the highest teaching efficacy scores on the TBS also had the highest STRS scores and PTRS scores. The teachers with the higher TBS scores (53\% were above the group mean) had bachelor's degrees with many courses or majors in child development or early childhood education. The research on teaching efficacy in primary and secondary teachers suggests that teaching efficacy significantly increases after students complete their supervised practice teaching prior to graduation (Woolfolk et al., 1990). The data in the present study suggests a similar pattern is possible for students in early childhood education, since $48 \%$ of the sample were early childhood majors and $45 \%$ reported taking many courses in child development or early childhood education. Establishing strong teaching efficacy may be easier, therefore, for novice teachers during extended pre-service training than for lesseducated teachers who seek practical experience and skill-development on-the-job. Employers may find it important to provide mentoring and an extended period of specific feedback to new teachers to assure higher teaching efficacy for teachers with less coursework in child development/early education.

The low teaching efficacy scores however, for the 46 teachers who reported at least one child with special needs in their classroom mirror those reported of other early childhood teachers (Boulton, 1997; File, 1994). These results suggest that the teachers feel less confidence in their ability to effectively meet the needs of these particular children. Despite increasing mean STRS scores for teacher-child relationships (all above the 
group mean) as the number of children reported with special needs increased from one to two, three, or four, the TBS scores for all these teachers remained below the group mean. It is possible that although these teachers seldom felt competent or confident in meeting the needs of these children, they were able to view each child as unique and establish positive relationships on an individual basis. If this is true, the relationship between teaching efficacy and teacher-child relationships would be called into question and provide greater support for other factors, such as parent-teacher relationships influencing teacher-child relationships.

\subsection{Parent-teacher relationships}

The positive correlations for all teachers, and the profiles for 24 teachers with the highest and 21 with the lowest TBS scores suggest that parent-teacher relationships (PTRS scores) were also related to teaching efficacy. Generally, higher teaching efficacy appears related to more positive parent-teacher relationships. Teachers more confident in their abilities may be able to establish better parent-teacher relationships; much as a child's secure attachment with a parent allows them to attach with other adults more easily. The direction of causality, however, is not clear, since strong and positive parent-teacher relationships may serve to boost a teacher's efficacy. Positive feedback from parents may increase a teacher's confidence in his/her ability to meet children's developmental needs. But the low TBS scores for the 46 teachers of children with special needs, despite positive parent-teacher relationships would suggest that this is not always the case. In this latter group, child factors may have negatively influenced the TBS scores but not the parent-teacher or teacher-child relationships.

In the present study, the significant positive correlations between PTRS and STRS scores suggest teacherchild relationships are related to the quality of a teacher's relationship with a child's parent. Furthermore, the PTRS scores accounted for a significant amount of the variance in the analyses of teacher factors associated with teacher-child relationship scores on the STRS. Fifteen of the 18 teachers with the lowest STRS scores also had PTRS scores below the mean for this group of teachers studied. What is still unknown, however, is whether the positive parent-teacher relationship is an influence on or a result of positive teacherchild relationships. If a teacher likes a parent and finds interaction with her or him easy and supportive, will they view the child more positively? Conversely, can the challenges associated with a particular child in the classroom influence a teacher's views about her relationship with this child's parents? Is the parent viewed as responsible for the child's challenging behavior?
The more positive PTRS scores and more positive STRS scores for the 63 children who were reported to have a known disability or were being considered for referral to special education services suggest that child factors may have little influence on teacher-child or even parent-teacher relationships. These data support findings reported previously by Romer and Umbriet (1998) for early interventionists. It is possible, however, given the overall results showing positive correlations and predictive nature of parent-teacher relationships, that the parent-teacher relationship played some role in influencing these 46 teachers' relationships with the 63 children who had special needs. Despite their low efficacy scores, these teachers may have benefited from support and communication with parents that encouraged them to focus positively on the individual child with special needs, resulting in higher STRS scores.

\section{Limitations and future directions}

Several suggestions emerge from this research for future studies on related topics of teacher-child relationships. First, all information obtained in the present study relied on teachers' self-reports and only quantitative information was included. The lack of independence between factors in a self-report process prompts a cautious interpretation of the results. Bias can enter the teachers' self-ratings following a particularly challenging day with one child or parent and can influence the report of overall relationships. Furthermore, some teacher-child relationship issues cannot be totally explored by using quantitative research. For instance, whether a teacher tolerates a behavior from one child but not from another or why a teacher with the lowest degree, no training in child development, and with the least experience had the highest teaching efficacy, are questions that cannot be answered using quantitative data alone. Objective information on how different teachers manage their communication or interactions with some or all children and parents or with a particular child or parent would be helpful in understanding how to promote positive teacher-child and parent-teacher relationships. Despite these limitations, however, the present study still provides useful information about factors influencing teacher-child relationships. Clearly selfreport has some value when the topic is perceived relationships and (teaching) efficacy (Birch \& Ladd, 1997; Howes, 2000). But further research is needed to explore how environmental factors as well as other child and teacher factors can influence the teacherchild and parent-teacher relationships, especially for teachers of children with special needs. 


\section{Conclusions}

Teachers' educational training has again been identified as influencing teacher-child interaction and relationships. The present study, however, expands our knowledge of teacher factors related to these relationships to include teaching efficacy and parent-teacher relationships as additional factors for consideration. As noted earlier, since no single factor (child, environment, or teacher) can explain each teacher-child relationship, we should consider all possible factors that can help us to prevent or improve negative teacherchild relationships with young children. The parentteacher relationship was the most significant teacher factor to explain the teacher-child relationships in the present study and should therefore continue to receive our attention in pre-service training and new staff orientation programs. The association between teaching efficacy and teacher-child relationships also suggests that we should look to empower teachers with strategies that can make them feel effective and productive in working with all children, including those with challenging behaviors and histories of negative parent-child relationships. Finally, the challenges of children with special needs need not negatively influence a teacher's relationship with these children. A positive relationship with the parents of these children may act as an antidote when teachers feel less than confident about their own abilities to address adequately the children's unique demands and needs.

Given the influence teacher-child relationships can have on child outcomes and school success, it is essential that we look to influence every possible variable that can impact the quality of teacher-child relationships. Teacher training programs can benefit from attending to these teacher factors in preparing students for a teaching role in childcare and preschool settings. In the long run, this could help professionals prevent or reduce early school maladjustment for young children, especially for those at risk for or currently having social interaction problems.

Continued study of the factors contributing to the quality of teacher-child relationships in preschool age children is encouraged. The predictive value of specific child and environmental factors should be explored given the relatively smaller role teacher factors appear to play. In addition, the influence of training on teaching efficacy and parent-teacher relationships, in particular, needs further study to show causal as well as correlational relationships. In the meantime, training programs and program directors would be well advised to look beyond the child as the source of influence in all successful and challenging teacher-child re- lationships. Clearly the teacher has some responsibility and ability to influence these important first teacherchild relationships, and partnerships with parents may provide the needed support to do so. Recognizing the influence of the parent-teacher meso-system on the micro-systems of parent-child and teacher-child interactions and the child's developmental outcomes could be critical in assuring the children's future success in social and school settings.

\section{References}

Arnett, J. (1989). Caregivers in day-care Centers: Does training matter? Journal of Applied Developmental Psychology 10, 541-552.

Arnold, H., McWilliams, L., \& Arnold, H. (1998). Teacher discipline and child misbehavior in day care: Untangling causality with correlational data. Developmental Psychology 34(2), 276-287.

Bandura, A. (1995). Self-efficacy in changing societies. New York, NY: Cambridge University Press.

Birch, S., \& Ladd, W. (1997). The teacher-child relationship and children's early school adjustment. Journal of School Psychology 35(1), 61-79.

Berk, L, \& Winsler, A. (1995). Scaffolding children's learning: Vygotsky and early childhood education. Washington, DC: NAEYC.

Bernhard, J., Lefebvre, M., Kilbride, K., Chud, G., \& Lange, R. (1998). Troubled relationships in early childhood education: Parent-teacher interactions in ethno-culturally diverse child care settings. Early Education and Development 9(1), 5-28.

Boulton, M. (1997). Teachers' views on bullying: Definitions, attitudes and ability to cope. British Journal of Educational Psychology 67, 223-233.

Bronfenbrenner, U. (1979). The ecology of human development: Experiments by nature and design. Cambridge, MA: Harvard University Press.

Bronson, M., Peirson, D., \& Tivnan, T. (1984). The effects of early education on children's competence in elementary school. Evaluation Review 8, 615-629.

Bullock, J. (1993). Children's temperament: How can teachers and classrooms be more responsive? Early Child Development and Care 88, 53-59.

Christenson, S. (2000). Families and schools: Rights. responsibilities, resources and relationships. In R. C. Pianta \& M. J. Cox (eds.), The transition to kindergarten (pp. 143-177). Baltimore. MD: Brookes Publishing.

Chung, L. C. (2000). A study of teacher factors in teacherchild relationships with preschool children. Adaptations of Parent-Teacher Relationship Scales. Unpublished doctoral dissertation, University of Nebraska, Lincoln. 
Cmic, K., Greenberg, M., \& Slough, N. (1986). Early stress and social support influences on mothers' and high-risk infants' functioning in late infancy. Infant Mental Health Journal 7, 19-48.

Dunst, C, Trivette, C., \& Deal, A. (1988). Enabling and empowering families: Principles and guidelines for practice. Cambridge, MA: Brookline Press.

Egeland, B., Kalkoske, M., Gottesman, N., \&. Erickson, F. (1990). Preschool behavior problems: Stability and factors accounting for change. Journal of Child Psychology and psychiatry 31(6), 891-900.

Elicker, J., Noppe, I., \& Noppe, L. (1997). The Parent-Child Caregiver Relationship Scale: Rounding out the relationship system in infant child care. Early Education and Development 8(1), 833-899.

Emery, R. E. (1982). Interparental conflict and the children of discord and divorce. Psychological Bulletin 92, 310-330.

Fagan, J. (1990). The interaction between child sex and temperament in predicting behavior problems of preschool-age children in day care. Early Child Development and Care 59, 1-9.

File, N. (1994). Children's play, teacher-child interactions, and teacher beliefs in integrated early childhood programs. Early Childhood Research Quarterly 9, 223-240.

Gibson, S., \& Dembo, M. (1984). Teacher efficacy: A construct validation. Journal of Educational Psychology 76, 569-582.

Greenman, J. (1988). Caring spaces, learning spaces: Children's environments that work. Redmond, WA: Exchange Press Inc.

Hohmann, M., \& Weikart, P. (1995). Educating young children. Ypsilanti, MI: High/Scope Press.

Howes, C. (1997). Children's experiences in center-based child care as a function of teacher background and adult:child ratio. Merrill-Palmer Quarterly 43(3), 404-425.

Howes, C. (2000). Social-emotional classroom climate in child care, teacher--child relationships and children's second-grade peer relations. Social Development 9(2), 191-204.

Howes, C., \& Hamilton, C. (1992). Children's relationships with child care teachers: Stability and concordance with parental attachments. Child Development 63, 867-878.

Howes, C., Matheson, C., \& Hamilton, E. (1994). Maternal, teacher, and child care history correlates of children's relationships with peers. Child Development 65, 264-273.

Howes, C., \& Ritchie, S. (1998). Changes in teacher-child relationships. Early Education and Development 9(4), 411-422.

Howes, C., Whitebook, M., \& Phillips, D. (1992). Teacher characteristics and effective teaching in child care: Findings from the national staffing study. Child \& Youth Care Forum 21(6), 399-414.
Keogh, B., \& Burstein, N. (1988). Relationship of temperament to preschoolers' interactions with peers and teachers. Exceptional Children 54(5), 456-461.

Kontos, S. (1987). The attitudinal context of family day care relationships. In D. Peters \& S. Kontos (eds.), Continuity and discontinuity of experience in children: Annual advances in applied developmental psychology: Vol. 2 (pp. 91113). Norwood, NJ: Ablex Publishing.

Kontos, S., Raikes, H., \& Woods, A. (1983). Early childhood staff attitudes toward their parent clientele. Child Care Quarterly 12, 45-58.

Kontos, S., \& Wilcox-Herzog, A. (2001). How do education and experience affect teachers of young children? Young Children 56(4), 85-91.

McGaha, C., Snow, C., \&. Teleki, J. (2001). Family childcare in the United States: A comparative analysis of 1981 and 1998 state regulations. Early Childhood Education Journal 28(4), 251-255.

McGee, G., Daly, T., Izeman, G., Mann, H., \& Risley, R. (1991). Use of classroom materials to promote preschool engagement. Teaching Exceptional Children 24, 44-47.

Mill, D., \&. Romano-White, D. (1999). Correlates of affectionate and angry behavior in child care educators of preschool-aged children. Early Childhood Research Quarterly 14(2), 155-178.

National Center for Education Statistics. (1998). Digest of education statistics. Washington, DC: NCES.

Nimetz, S. L. (1992). Continuity from mother-child to teacher-child relationships in four-year-olds and the prediction of kindergarten adjustment. Unpublished dissertation, University of Virginia.

Nordquist, M., \& Twardosz, S. (1990). Preventing behavior problems in early childhood special education classrooms through environmental organization. Education and Treatment of Children 13(4), 274-287.

Oakes, B., \& Caruso, A. (1990). Kindergarten teachers' use of developmentally appropriate practices and attitudes about authority. Early Education and Development 1(6), $445-457$.

Olds, A. (1982). Designing play environments for children under 3. Topics in Early Childhood Special Education 2(3), 87-95.

Paget, K., Nagle, R., \& Martin, R. (1984). Interrelationships between temperament characteristics and first grade teacher-child interactions. Journal of Abnormal Child Psychology 12(4), 547-560.

Pianta, R. (1992). The Student-Teacher Relationship Scale. Charlottesville, VA: University of Virginia.

Pianta, R. (1996). Manual and scoring guide for the studentteacher relationship scale. Unpublished manuscript.

Pianta, R., \& Nimetz, L. (1991). Relationships between teachers and children: Associations with behaviors at home and in the classroom. Journal of Applied Developmental Psychology 12, 379-393. 
Pianta, R., Nimetz, L., \& Bennett, E. (1997). Mother-child relationships, teacher-child relationships, and school outcomes in preschool and kindergarten. Early Childhood Research Quarterly 12, 263-280.

Pianta, R., Steinberg, S., \& Rollins, B. (1995). The first two years of school: Teacher-child relationship and deflections in children's classroom adjustment. Development and Psychopathology 7, 295-312.

Pianta, R., \& Walsh, D. (1996). High risk children in schools: Constructing sustaining relationships. New York, NY: Routledge Publishing.

Quay, L., \& Jarrett, O. (1986). Teachers' interactions with middle and lower SES preschool boys and girls. Journal of Educational Psychology 78(6), 595-598.

Roberts, E., Bailey, D., \& Nychka, B. (1991). Teachers' use of strategies to facilitate the communication of preschool children with disabilities. Journal of Early Intervention 15(4), 358-376.

Romer, E., \&. Umbriet, J. (1998). The effects of family-centered service coordination: A social validity study. Journal of Early Intervention 21(2), 95-110.

Schaffer, H., \& Liddell, C. (1984). Adult-child interaction under dyadic and polyadic conditions. British Journal of Developmental Psychology 2, 33-42.

Soodak, C., \& Podell, M. (1996). Teacher efficacy: Toward the understanding of a multi-faceted construct. Teaching and Teacher Education 12(4), 401-411.
Sroufe, L. (1983). Infant-caregiver attachment and patterns of adaptation in preschool: The roots of maladaptation and competence. The Minnesota Symposia on Child Development 16, 41-83.

Stipek, D., \& Sanborn, M. (1985). Teachers' task-related interactions with handicapped and nonhandicapped preschool children. Merrill Palmer Quarterly 31(3), 285-300.

Van der Werfhost, H. (1986). Temperament and teacherchild interaction. In G. Kohnstamm (ed.), Temperament discussed: Temperament and development in infancy and childhood (pp. 141-147). The Netherlands: University of Leiden.

White, K. (1993). Does a degree make a difference? A comparison of interactions between degreed and nondegreed early childhood educators and their fouryear-old children. Early Child Development and Care 96, 147-160.

Whitebook, M., Howes, C., \& Philips, D. (1998). A decade following the national child care staffing study. Oakland. CA: Center for Childcare Workforce.

Woolfolk, E., Rosoff, B., \& Hoy, W. (1990). Teachers' sense of efficacy and their beliefs about managing students. Teaching and Teacher Education 6(2), 137-148. 